06

\title{
Физико-химический анализ структуры и свойств нанокомпозитов полимер/углеродные нанотрубки, полученных из раствора
}

\author{
(C) Г.В. Козлов, И.В. Долбин \\ Кабардино-Балкарский государственный университет им. Х.М. Бербекова, \\ 360004 Нальчик, Россия \\ e-mail: i_dolbin@mail.ru
}

Поступило в Редакцию 27 января 2021 г.

В окончательной редакции 2 марта 2021 г.

Принято к публикации 11 марта 2021 г.

Для описания вязкости водных суспензий углеродных нанотрубок использована структурная (фрактальная) модель, ранее применявшаяся для полимерных растворов. Указанная модель адекватно трактует зависимость вязкости суспензии от концентрации углеродных нанотрубок. При достижении порога перколяции этого нанонаполнителя наблюдается резкий рост вязкости водных суспензий. Модель также адекватно отражает зависимость вязкости от геометрии углеродных нанотрубок. Знание структуры нанонаполнителя, характеризуемой ее фрактальной размерностью, позволяет прогнозировать степени усиления твердофазных полимерных нанокомпозитов.

Ключевые слова: углеродные нанотрубки, водная суспензия, вязкость, фрактальная размерность, порог перколяции.

DOI: $10.21883 / J T F .2021 .08 .51099 .17-21$

\section{Введение}

Углеродные нанотрубки (УНТ) обладают специфической сильно анизотропной структурой, что определяет их свойства: высокое аспектное отношение и относительно невысокий поперечный модуль упругости [1]. Поэтому УНТ в различных состояниях (растворе, суспензии, расплаве, твердой фазе) образуют кольцеобразные формирования, которые являются структурным аналогом макромолекулярных клубков разветвленных полимерных цепей [2]. К тому же было экспериментально [2] и теоретически [3] продемонстрировано, что указанные формирования УНТ являются фрактальными объектами с размерностью $D_{f}$, варьирующейся в достаточно широком диапазоне: $D_{f}=1-3$. Эти обстоятельства позволяют использовать для описания структуры УНТ в разных состояниях хорошо разработанные методы как классической [4], так и фрактальной [5] физической химии полимерных растворов. Так, авторы [6] исследовали водные суспензии УНТ и обнаружили, что поведение их вязкости корректно описывается в рамках хорошо известных уравнений Шульца-Блашке и Марка-Куна-Хаувинка. Однако для практических целей необходимо прогнозирование структуры УНТ при получении пленок полимерных нанокомпозитов из раствора, т.е. при изменении среды, окружающей УНТ, от растворителя к полимеру, и дальнейшее предсказание свойств твердофазных нанокомпозитов на этой основе. В настоящей работе указанные задачи решаются с привлечением методов фрактальной физической химии [5] и механики [7].

\section{1. Методика эксперимента}

В настоящей работе использованы экспериментальные данные [6] для водных суспензий многослойных углеродных нанотрубок (МУНТ) с двумя длинами (0.37 и $1.10 \mu \mathrm{m})$ и диаметром $10 \pm 2 \mathrm{~nm}$. Образование стабильных водных суспензий МУНТ достигалось применением их обработки кислотами. Вязкость указанных суспензий как функция концентрации МУНТ в интервале 0.00005-0.012 по объему определена на полуавтоматической системе Lauda Viscoboy 2 с использованием капиллярных вискозиметров Уббелоде Schott Geräte при температуре испытаний $302 \mathrm{~K}$, поддерживаемой с помощью водяной ванны [6].

\section{2. Результаты и их обсуждение}

Используемые авторами [6] уравнения Шульца-Блашке и Марка-Куна-Хаувинка не содержат структурных характеристик для макромолекулярных клубков полимеров и кольцеобразных формирований УНТ. Поэтому в настоящей работе для описания вязкости водных сус-

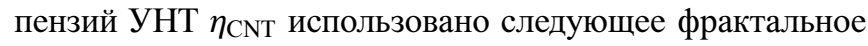
соотношение $[5,8]$ :

$$
\eta_{\mathrm{CNT}}=c(\alpha) \frac{M M^{\left(d-D_{f}\right) / D_{f}}}{m_{0}^{d / D_{f}}},
$$

где $c(\alpha)$ - константа, зависящая от коэффициента набухания $\alpha$ и равная в рассматриваемом случае 0.049 , $M M$ - молекулярная масса УНТ, $d$ - размерность евклидова пространства, в котором рассматривается фрактал (очевидно, в нашем случае $d=3$ ), $D_{f}-$ 


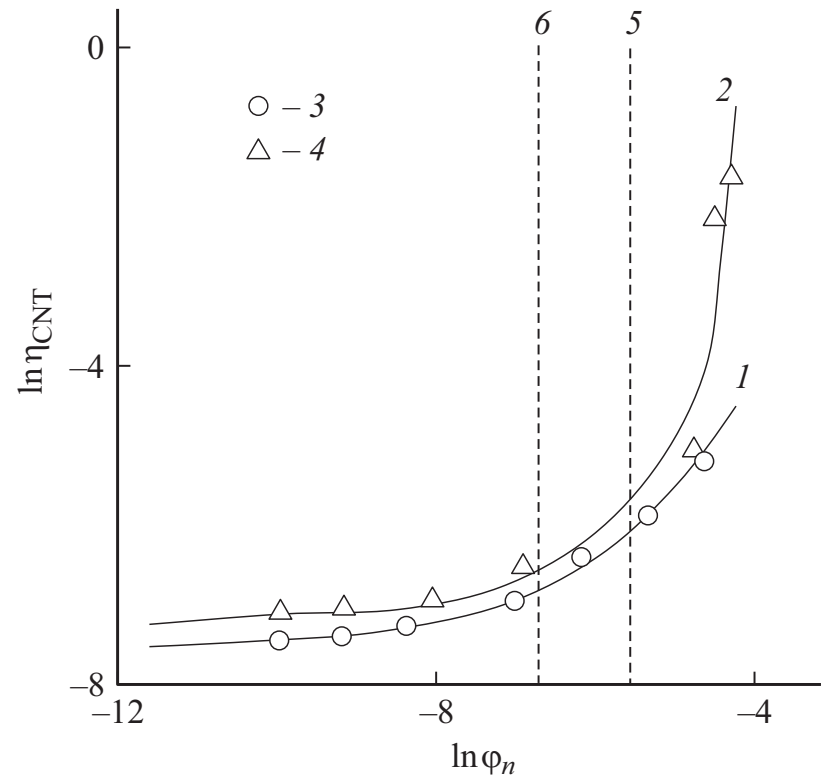

Рис. 1. Рассчитанные согласно уравнению (1) $(1,2)$ и полученные экспериментально $(3,4)$ зависимости вязкости водной суспензии УНТ $\eta_{\mathrm{CNT}}$ от объемного содержания УНТ $\varphi_{n}$ в двойных логарифмических координатах для коротких $(1,3)$ и длинных $(2,4)$ нанотрубок и их порог перколяции $(5,6)$ соответственно.

фрактальная размерность кольцеобразного формирования УНТ, $m_{0}$ - молекулярная масса „участка жесткости“ УНТ (аналог сегмента Куна для макромолекулярного клубка).

Рассмотрим методы определения параметров $M M, D_{f}$ и $m_{0}$, входящих в уравнение (1). Молекулярная масса $M M$ определяется следующим образом [9]:

$$
M M=V_{\mathrm{CNT}} \rho_{\mathrm{CNT}} N_{a},
$$

где $V_{\mathrm{CNT}}$ - объем УНТ, определяемый из геометрический соображений, $\rho_{\mathrm{CNT}}-$ еe плотность, равная $1500 \mathrm{~kg} / \mathrm{m}^{3}$ [6], $N_{a}$ - число Авогадро. Величина $M M$ равна $5.4 \cdot 10^{4} \mathrm{~g} / \mathrm{mol}$ для длинных УНТ и $1.8 \cdot 10^{4} \mathrm{~g} / \mathrm{mol}-$ для коротких.

Величина размерности $D_{f}$ определена с помощью уравнения [3]

$$
R_{\mathrm{CNT}}=3.4\left(\varphi_{n}\right)^{-1 /\left(d-D_{f}\right)},
$$

где $R_{\mathrm{CNT}}$ - радиус кольцеобразных формирований УНТ, который можно рассчитать с помощью следующего соотношения [3]:

$$
\left(2 R_{\mathrm{CNT}}\right)^{3}=\frac{\pi r_{\mathrm{CNT}}^{2} L_{\mathrm{CNR}}}{\varphi_{n}},
$$

где $r_{\mathrm{CNT}}$ и $L_{\mathrm{CNT}}-$ радиус и длина УНТ соответственно, $\varphi_{n}$ - объемное содержание УНТ, которое для рассматриваемых водных суспензий УНТ приведено в работе [6].

Сравнение рассчитанных согласно предложенной методике и приведенных в работе [6] зависимостей
$\eta_{\mathrm{CNT}}\left(\varphi_{n}\right)$ в двойных логарифмических координатах приведено на рис. 1. Их сравнение показало хорошее соответствие обоих наборов данных для УНТ с двумя разными длинами -0.37 и $1.10 \mu \mathrm{m}$. Как следует из приведенного графика, при $\varphi_{n} \approx 0.0015$ начинается резкое увеличение вязкости водной суспензии УНТ по мере повышения их содержания. Этот переход можно связать с достижением величиной $\varphi_{n}$ порога перколяции УНТ $\varphi_{c}$, после которого сильно анизотропные нанотрубки формируют непрерывный перколяционный каркас. Наиболее просто оценить величину $\varphi_{c}$ можно следующим образом [10]:

$$
\varphi_{c}=0.6\left(\frac{D_{\mathrm{CNT}}}{L_{\mathrm{CNT}}}\right),
$$

где $D_{\mathrm{CNT}}$ - наружный диаметр УНТ.

Полученные значения $\varphi_{c}$ показаны на рис. 1 вертикальными штриховыми линиями и хорошо согласуются с началом резкого повышения вязкости водной суспензии УHT.

Процесс получения пленок нанокомпозитов из растворов в органических растворителях характеризуется испарением последних, что приводит к изменению среды, окружающей УНТ, от молекул растворителя к макромолекулярным клубкам полимерной матрицы. Оценить степень влияния такого изменения на структуру УНТ в полимерной матрице, характеризуемую размерностью $D_{f}$, можно в рамках модели [11] применением следующего уравнения:

$$
D_{f}=\frac{d\left(2 D_{f}^{m}-D_{f}^{n a n}\right)}{d+2\left(D_{f}^{m}-D_{f}^{n a n}\right)},
$$

где $D_{f}^{m}$ и $D_{f}^{n a n}-$ фрактальная размерность макромолекулярного клубка полимерной матрицы, принятая равной $1.80[5]$, и исходного нанонаполнителя $\left(D_{f}^{n a n}=1.0\right)$ соответственно.

Оценки, согласно уравнениям (3) и (6), продемонстрировали, что изменение окружающей УНТ среды от низкомолекулярного растворителя (в рассматриваемом случае - воды) к высокомолекулярной полимерной матрице приводит к существенному росту фрактальной размерности их структуры, особенно ярко выраженному при малых концентрациях УНТ (рис. 2).

Оценку величины $D_{f}$, согласно уравнению (3), можно проверить использованием формулы (6) с заменой размерности на размерность низкомолекулярного растворителя (воды) $D_{f}^{\mathrm{H}_{2} \mathrm{O}}$, полагая последнюю равной нулю. Это означает, что молекулы $\mathrm{H}_{2} \mathrm{O}$ рассматриваются как точечные объекты. На рис. 2 зависимость $D_{f}\left(\varphi_{n}\right)$, pacсчитанная при условии $D_{f}^{m}=D_{f}^{\mathrm{H}_{2} \mathrm{O}}=0$, показана штриховой линией, и из сравнения кривых 1 и 3 следует их достаточно хорошее соответствие: среднее расхождение составляет $\sim 10 \%$. Одной из причин указанного расхождения может быть допущение условия $D_{f}^{\mathrm{H}_{2} \mathrm{O}}=0$, хотя в настоящее время известно, что молекулы воды могут формировать кластеры с размерностью $D_{f}^{\mathrm{H}_{2} \mathrm{O}}>0$ [12].

Используя значения фрактальной размерности Df УНТ в полимерной матрице, определенные согласно 
уравнению (6), можно предсказать степень усиления пленочных образцов полимер/УНТ в рамках фрактальной модели усиления полимерных нанокомпозитов, основное соотношение которой имеет следующий вид [13]:

$$
\frac{E_{n}}{E_{m}}=1+11\left(\varphi_{n}\right)^{1 / D_{f}},
$$

где $E_{n}$ и $E_{m}-$ модули упругости нанокомпозита и матричного полимера соответственно (отношение $E_{n} / E_{m}$ принято называть степенью усиления нанокомпозита).

В качестве экспериментальных данных для проверки корректности прогнозирования, согласно предложенной методике, были использованы результаты работы [14] для нанокомпозитов поливиниловый спирт/углеродные нанотрубки (ПВС/УНТ), полученные из растворов указанных нанокомпозитов в дэионизированной воде. Эти экспериментальные результаты наиболее близки к полученным в настоящей работе теоретическим методом. На рис. 3 приведено сравнение полученных экспериментально для нанокомпозитов ПВС/УНТ и рассчитанных, согласно уравнению (7), зависимостей степени усиления $E_{n} / E_{m}$ от объемного содержания нанонаполнителя $\varphi_{n}$, которое показало их хорошее соответствие (среднее расхождение теории и эксперимента составляет менее 7\%). Указанное соответствие предполагает корректность выполненного в настоящей работе теоретического анализа.

И в заключение укажем разные тенденции изменения вязкости водных суспензий УНТ и степени усиления полимерных нанокомпозитов: если после достижения величиной $\varphi_{n}$ порога перколяции УНТ $\varphi_{c}$ наблюдается резкий рост вязкости суспензии УНТ (рис. 1), то при

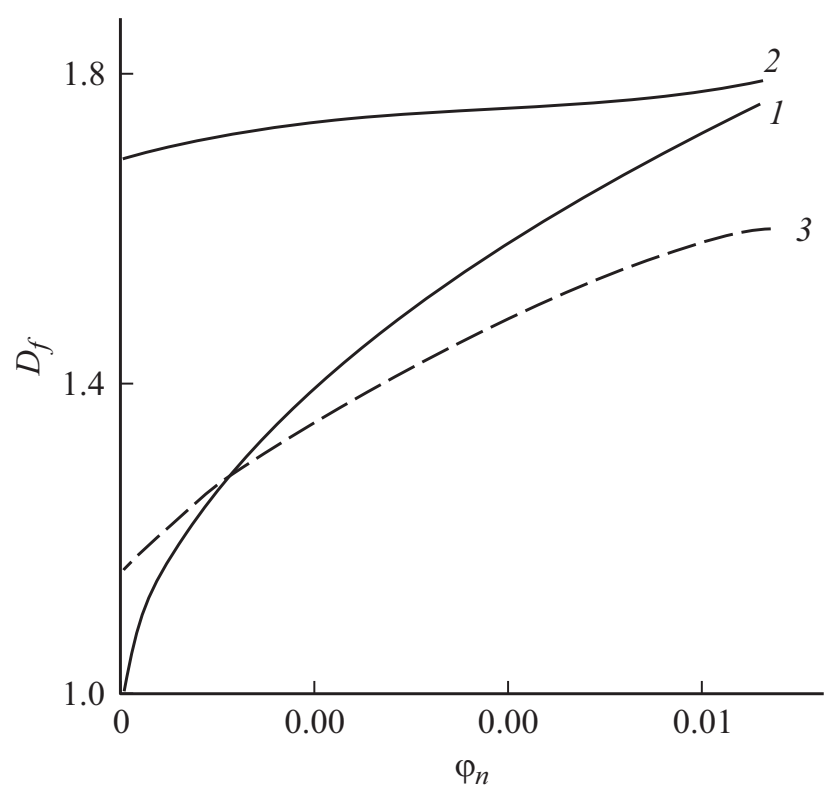

Рис. 2. Зависимости фрактальной размерности УНТ $D_{f}$ от их объемного содержания $\varphi_{n}$, рассчитанные согласно уравнениям (3) (1) и (6) (2). Штриховая линия 3 - расчет гипотетической зависимости $D_{f}\left(\varphi_{n}\right)$, согласно уравнению (6), при условии $D_{f}^{m}=0$.

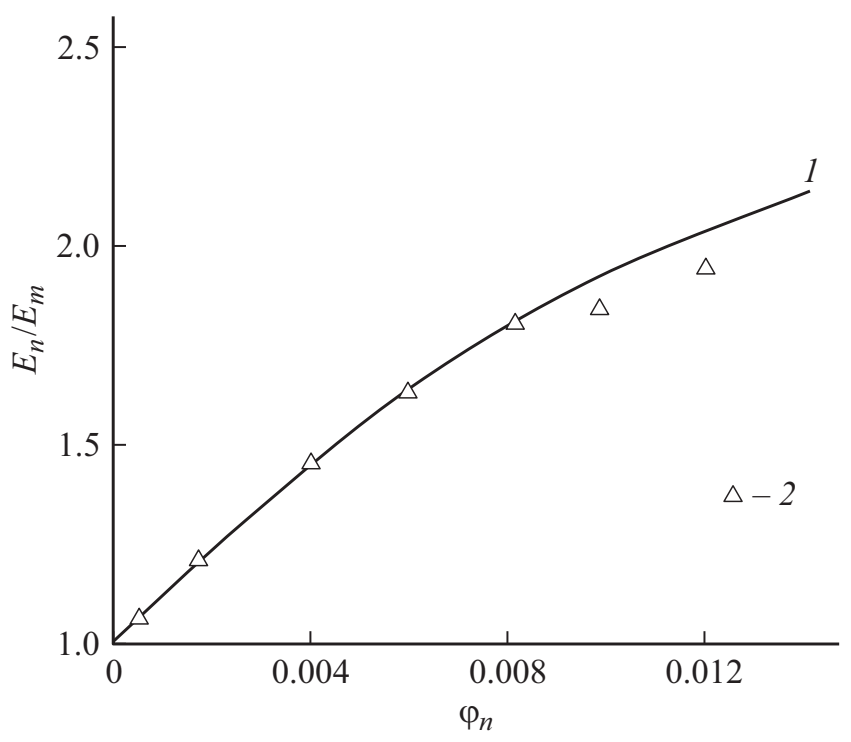

Рис. 3. Зависимости степени усиления $E_{n} / E_{m}$ от объемного содержания нанонаполнителя $\varphi_{n}$, рассчитанная, согласно уравнению (7), (1) и полученная экспериментально (2) [14] для нанокомпозитов ПВС/УНТ.

этих же условиях степень усиления нанокомпозитов замедляет свое увеличение, стремясь к асимптотической величине (рис. 3).

\section{Заключение}

Таким образом, результаты работы продемонстрировали, что предложенная фрактальная модель корректно описывает экспериментально полученные зависимости вязкости водной суспензии УНТ от их содержания. При этом указанная модель включает только геометрические и структурные показатели этого типа нанонаполнителя. Среда, окружающая нанотрубки, в значительной степени влияет на их структуру. Достижение содержанием нанонаполнителя его порога перколяции определяет резкий рост вязкости водной суспензии УНТ. Наиболее важным результатом следует считать возможность прогнозирования характеристик конечных нанокомпозитов по структурным показателям водных суспензий нанонаполнителя (УHT).

\section{Конфликт интересов}

Авторы заявляют, что у них нет конфликта интересов.

\section{Список литературы}

[1] M. Moniruzzaman, K.I. Winey. Macromolecules, 39 (16), 5194 (2006). DOI: 10.1021/ma060733p

[2] D.W. Schaefer, R.S. Justice. Macromolecules, 40 (24), 8501 (2007). 
[3] А.К. Микитаев, Г.В. Козлов. ДАН, 462 (1), 41 (2015). [A.K. Mikitaev, G.V. Kozlov. Dokl. Phys., 60 (5), 203 (2015). DOI: $10.1134 / \mathrm{S} 102833581505002 \mathrm{X}$

[4] В.П. Будтов. Физическая химия растворов полимеров (Химия, СПб., 1992)

[5] G.V. Kozlov, I.V. Dolbin, G.E. Zaikov. The Fractal Physical Chemistry of Polymer Solutions and Melts (Apple Academic Press, Toronto, New Jersey, 2014)

[6] M.S.P. Shaffer, A.H. Windle. Macromolecules, 32 (20), 6864 (1999). DOI: 10.1021/ma990095t

[7] Л.Б. Атлуханова, Г.В. Козлов. Физикохимия нанокомпозитов полимер-углеродные нанотрубки („Спутник+“, М., 2020)

[8] Г.В. Козлов, И.В. Долбин. Высокомолек. соед. Б, 44 (1), 115 (2002).

[9] Г.В. Козлов, Д.С. Сандитов. Ангармонические эффекты и фбизико-механические свойства полимеров (Наука, Новосибирск, 1994)

[10] L. Berhan, A.M. Sastry. Phys. Rev. E, 75 (4), 041120 (2007). DOI: 10.1103/PhysRevE.75.041120

[11] H.G.E. Hentschel, J.M. Deutch. Phys. Rev. A, 29 (3), 1609 (1984). DOI: org/10.1103/PhysRevA.29.1609

[12] R.K. Chakraborti, K.H. Gardner, J.E. Atkinson, J.E.V. Benschoten. Water. Res., 37 (4), 873 (2003).

DOI: $10.1016 / \mathrm{s} 0043-1354(02) 00379-2$

[13] Л.Б. Атлуханова, Г.В. Козлов, И.В. Долбин. Материаловедение, 7, 19 (2019).

DOI: 10.31044/1684-579x-2019-0-7-19-22

[14] M. Cadek, J.N. Coleman, V. Barron, K. Hedicke, W.J. Blau. Appl. Phys. Lett., 81 (27), 5123 (2002).

DOI: $10.1063 / 1.1609255$ 